\title{
Nanoclays for polymer nanocomposites, paints, inks, greases and cosmetics formulations, drug delivery vehicle and waste water treatment
}

\author{
HASMUKH A PATEL, RAJESH S SOMANI, HARI C BAJAJ* and RAKSH V JASRA \\ Silicates and Catalysis Division, Central Salt and Marine Chemicals Research Institute, G.B. Marg, \\ Bhavnagar 364 002, India
}

MS received 25 October 2005

\begin{abstract}
An overview of nanoclays or organically modified layered silicates (organoclays) is presented with emphasis placed on the use of nanoclays as the reinforcement phase in polymer matrices for preparation of polymer/layered silicates nanocomposites, rheological modifier for paints, inks and greases, drug delivery vehicle for controlled release of therapeutic agents, and nanoclays for industrial waste water as well as potable water treatment to make further step into green environment. A little amount of nanoclay can alter the entire properties of polymers, paints, inks and greases to a great extent by dispersing 1nm thick layered silicate throughout the matrices. The flexibility of interlayer spacing of layered silicates accommodates therapeutic agents which can later on be released to damaged cell. Because the release of drugs in drug-intercalated layered materials is controllable, these new materials have a great potential as a delivery host in the pharmaceutical field. The problem of clean water can be solved by treating industrial and municipal waste water with organoclays in combination with other sorbents like activated carbon and alum. Organoclays have proven to be superior to any other water treatment technology in applications where the water to be treated contains substantial amounts of oil and grease or humic acid.
\end{abstract}

Keywords. Layered silicates; nanocomposites; rheological modifier; drug delivery; waste water.

\section{Introduction}

Organically modified layered-silicates or nanoclays have become an attractive class of organic-inorganic hybrid materials because of their potential use in wide range of applications such as in polymer nanocomposites, rheological modifier in paints, inks, greases and cosmetics, adsorbent for toxic gases, effluent treatment and drug delivery carrier. The generic term, layered silicates, refers to natural clays as well as synthesized layered silicates such as montmorillonite, laponite and hectorite.

The most commonly used clay in the synthesis of polymer nanocomposites is montmorillonite (MMT) which is the major constituent of bentonite. It is well known that filler anisotropy, i.e. large length to diameter ratio (aspect ratio), is especially favourable in matrix reinforcement. Due to unique structure of montmorillonite, the mineral platelet thickness is only one nanometer, although its dimensions in length and width can be measured in hundreds of nanometers, with a majority of platelets in 200-400 nm range after purification. Due to very small size and

\footnotetext{
*Author for correspondence (hcbajaj@csmcri.org)
}

thickness of the platelets, a single gram of clay contains over a million individual platelets. The term polymer layered silicate nanocomposites describes a class where the reinforcing phase, in the shape of platelets, has only nanolevel dimensions. There is substantial improvement in mechanical and physical properties of nanocomposites and this too at a very low silicate content (3-6 wt\%). Improved mechanical and thermal properties are of interest for under-the-hood applications in the automotive industry (Fukushima and Inagaki 1987). Excellent barrier properties combined with good transparency make these materials ideal for packaging applications (Okada et al 1990, Okada and Usuki 1995; Giannelis 1996; Giannelis et al 1999; LeBaron et al 1999; Vaia et al 1999; Biswas and Sinha Ray 2001). The era of polymer nanocomposites received an impetus after the work of a researcher from Toyota in 1987 (Fukushima and Inagaki 1987). Toyota discovered the possibility of synthesizing polymer nanocomposites based on nylon-6/organophilic montmorillonite clay that showed dramatic improvements in mechanical and physical properties and heat distortion temperature at very low content of layered silicate. The intercalation chemistry of polymers when mixed with appropriately modified layered silicate and synthetic layered silicates has long been known (Theng 1979). The field of polymer/ 
layered silicate nanocomposites has gained momentum by the observation of Vaia et al (1993) wherein they have shown that it is possible to melt-mix polymers with layered silicates, without the use of organic solvents. Today, efforts are being made globally for using nanoclays in almost all types of polymer matrices.

In addition to organically modified natural montmorillonite, synthetic layered silicates such as laponite, hectorite and saponite have been used as rheological modifiers in paints, inks, greases and cosmetics. Organoclays obtained by interaction of these layered silicates with ammonium or phosphonium salts act as thixotropic agent in the above applications. A small addition of nanoclays can greatly enhance the rheological properties of the paint system. These properties prevent pigment settling and sagging on vertical surfaces and gloss is minimally affected due to the low levels of addition. Thermal stability of grease is greatly enhanced by the addition of small amount of organoclays (Somani et al 1998, 2000). Nanoclays provide colour retention as well as good coverage in cosmetics and inks (Tatum and Wright 1988; Edwin 1990; Gadberry et al 1997). The organic binds to the ionic surfaces of layered silicates and converts it from a hydrophilic form to an oilwet, a hydrocarbon adsorbent material, ideal for water treatment applications. When used for water treatment, organoclays are commonly utilized in the upstream sector of the petroleum industry for removing hydrocarbons from refinery process water, but it has seen little use in petroleum production. Organoclays have also been tested for treating ground and surface water and for other toxic organic chemicals from pharmaceuticals and pesticides industries. Organoclays can offer dramatic performance improvements in many other adsorption applications, including removing oil, grease, heavy metals, and polychlorinated biphenyl; organic matter, such as humic and fulvic acids; polynuclear and polycyclic aromatics; and sparingly soluble hydrophobic, chlorinated organics. Removing radionuclides, including pertechnetate, from water is another application with tremendous potential (Slabaugh and Hanson 1969; Stockmeyer 1991; Bhatt et al 1996, 2005; Irene and Raymond 1998; Jasra et al 1999; ElNahhal and Safi 2004; Sanchez-Martin et al 2005; Sora et al 2005). Nanoclays are potentially useful materials in the field of controlled release of therapeutic agent to patients, where it acts as a drug vehicle. MMT could adsorb dietary toxins, bacterial toxins associated with gastrointestinal disturbance, hydrogen ions in acidosis, and metabolic toxins such as steroidal metabolites associated with pregnancy. All these conditions result in a host of common symptoms, including nausea, vomiting and diarrhea, most of which are typical symptoms of the side effects caused by anticancer drugs (Yuancai and Si-Shen 2005).

In the present review, the focus of discussion on nanoclays includes polymer-layered silicate nanocomposites, rheological modifier in paints, inks, greases and cosmetics, nanoclays as drug carrier in medicinal application and treating industrial waste water. The replacement of the inorganic exchangeable cations in the interlayer spacing of the layered silicates by alkyl ammonium surfactants can compatibilize the surface chemistry of the clay and the hydrophobic polymer matrix or liquor which is the key property of nanoclays suitable for above applications.

\section{Clays and their modification}

Clays are naturally occurring minerals with variability in their constitution depending on their groups and sources. The clays used for the preparation of nanoclays belong to smectite group clays which are also known as 2:1 phyllosilicates, the most common of which are montmorillonite $\left\{\mathrm{Si}_{4}\left[\mathrm{Al}_{1 \cdot 67} \mathrm{Mg}_{0 \cdot 33}\right] \mathrm{O}_{10}(\mathrm{OH})_{2} \cdot n \mathrm{H}_{2} \mathrm{O} \cdot \mathrm{X}_{0.33}=\mathrm{Na}, \mathrm{K}\right.$ or $\left.\mathrm{Ca}\right\}$ and hectorite $\left\{\mathrm{Si}_{4}\left[\mathrm{Mg}_{2 \cdot 7} \mathrm{Li}_{0 \cdot 3}\right] \mathrm{O}_{10}(\mathrm{OH})_{2} \cdot \mathrm{X}_{0 \cdot 4}=\mathrm{Na}\right\}$, where octahedral site is isomorphically substituted. Other smectite group clays are beidillite $\left\{\left[\mathrm{Si}_{3 \cdot 67} \mathrm{Al}_{0 \cdot 33}\right] \mathrm{Al}_{2} \mathrm{O}_{10}(\mathrm{OH})_{2} \cdot n \mathrm{H}_{2} \mathrm{O}\right.$. $\mathrm{X}_{0.33}=\mathrm{Na}, \mathrm{K}$ or $\left.\mathrm{Ca}\right\}$, nontronite $\left\{\left[\mathrm{Si}_{3 \cdot 67} \mathrm{Al}_{0.33}\right] \mathrm{Fe}_{2} \mathrm{O}_{10}\right.$ $(\mathrm{OH})_{2} \cdot \mathrm{X}_{0 \cdot 33}=\mathrm{Na}, \mathrm{K}$ or $\left.\mathrm{Ca}\right\}$ and saponite $\left\{\left[\mathrm{Si}_{3.67} \mathrm{Al}_{0.33}\right]\right.$ $\mathrm{Mg}_{3} \mathrm{O}_{10}(\mathrm{OH})_{2} \cdot \mathrm{X}_{0.33}=\mathrm{Na}, \mathrm{K}$ or $\left.\mathrm{Ca}\right\}$ in which tetrahedral site is isomorphically substituted. Crystal lattice of smectite group clay consists of a two-dimensional, $1 \mathrm{~nm}$ thick layers which are made up of two tetrahedral sheets of silica $\left(\mathrm{SiO}_{2}\right)$ fused to an edge-shaped octahedral sheet of alumina.

The lateral dimensions of these layers vary from $30 \mathrm{~nm}$ to several microns depending on the particular silicate. Stacking of the layers leads to a regular Van der Waals gap between them called the interlayer or gallery. Isomorphic substitution within the layer by $\mathrm{Mg}^{2+}, \mathrm{Fe}^{3+} / \mathrm{Fe}^{2+}$ or $\mathrm{Al}^{3+}$ generates negative charges that are normally counterbalanced by hydrated alkali or alkaline earth cations $\left(\mathrm{Na}^{+}\right.$, $\mathrm{K}^{+}, \mathrm{Ca}^{+}$, etc) residing in the interlayer as shown in schematic 1. Because of the relatively weak forces existing between the layers (due to the layered structure), intercalation of various molecules, and even polymer, is facile (Grim 1953; Theng 1974; Worrall 1986).

The clay platelets are truly nano-particulate. In the context of nanocomposites, it is important to note that the molecular weight of the platelets ( $c a .1 .3 \times 10^{8}$ Dalton) is considerably greater than that of typical commercial polymers, a feature which is often misrepresented in schematic diagrams of clay-based nanocomposites. In addition, platelets are not totally rigid, but have a degree of flexibility. The clays often have very high surface areas, up to hundreds of $\mathrm{m}^{2} / \mathrm{g}$ of clay. The clays are also characterized by their cation exchange capacities, which can vary widely and depends on source and type of clay. The purity of the clay can affect the final nanocomposite properties; due to this it is very important to have montmorillonite with minimum impurities of crystalline silica (quartz), amorphous silica, calcite, kaolin etc. The technique mainly used for purification of clays includes hydrocyclone, centrifugation, sedimentation method and chemical 


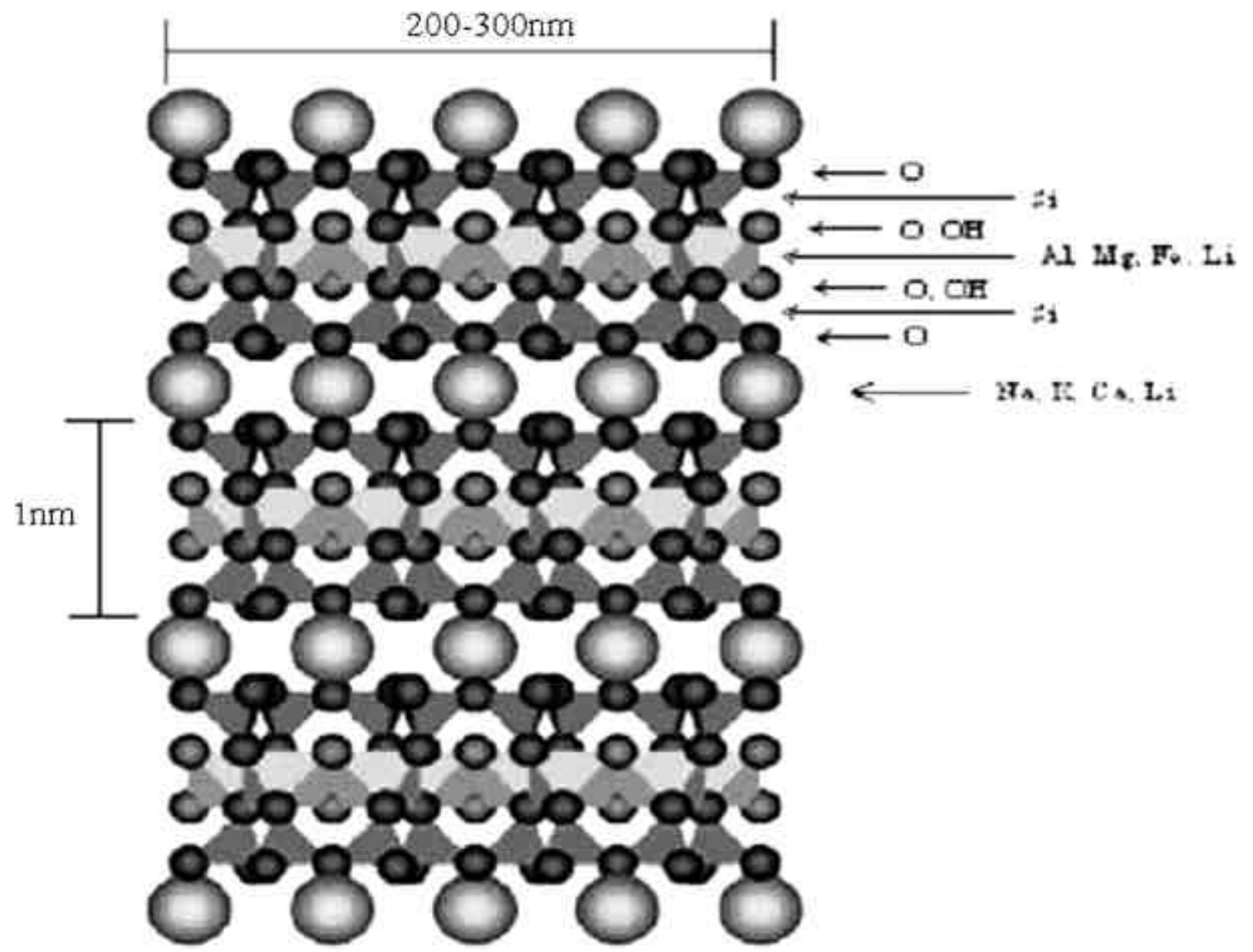

Schematic 1. The structure of $2: 1$ layered silicates.

treatment (Jasra et al 1995). Clays are inexpensive materials, which can be modified by ion exchange, metal/ metal complex impregnation, pillaring and acid treatment to develop catalysts with desired functionality (Taqui Khan et al 1991; Halligudi et al 1992; Boricha et al 1999; Jasra et al 1999).

Hectorite is a clay mineral similar in structure to MMT but with more negative charges on its surface. It is also hydrophilic swelling clay composed of silicate sheets which delaminate in water to provide an open three dimensional structure. Hectorite clays have the ability to thicken water and are widely used as rheological additives in waterborne coatings and inks.

One important consequence of the charged nature of the clays is that they are generally highly hydrophilic species and therefore, naturally incompatible with a wide range of non-polar systems. Organophilic clay (also known as nanoclay) can be obtained by simply the ionexchange reaction of hydrophilic clay with an organic cation such as an alkyl ammonium or phosphonium ion. The inorganic ions, relatively small (sodium), are exchanged with more voluminous organic onium cations (Lagaly 1986).

This ion-exchange reaction has two consequences; first, the gap between the single sheets is widened, enabling organic cations chain to move in between them and second, the surface properties of each single sheet are changed from being hydrophilic to hydrophobic or organophilic as shown in figure 1.

Clays and their modified organic derivatives are characterized using simple as well as modern characterization tools which include determination of chemical compositions by gravimetric analysis, inductively coupled plasma (ICP) or XRF, cation exchange capacity (CEC) using standard ammonium acetate method, surface area measurement, Fourier transform infrared spectroscopy (FT-IR), powdered X-ray diffraction (PXRD) and others. Generally, ionic formula is computed on the basis of its chemical compositions, charge density and cation exchange capacity of clays which provide information about the types of layered silicates. The instrumental techniques mainly, FT-IR and PXRD are basic methods for identification of 

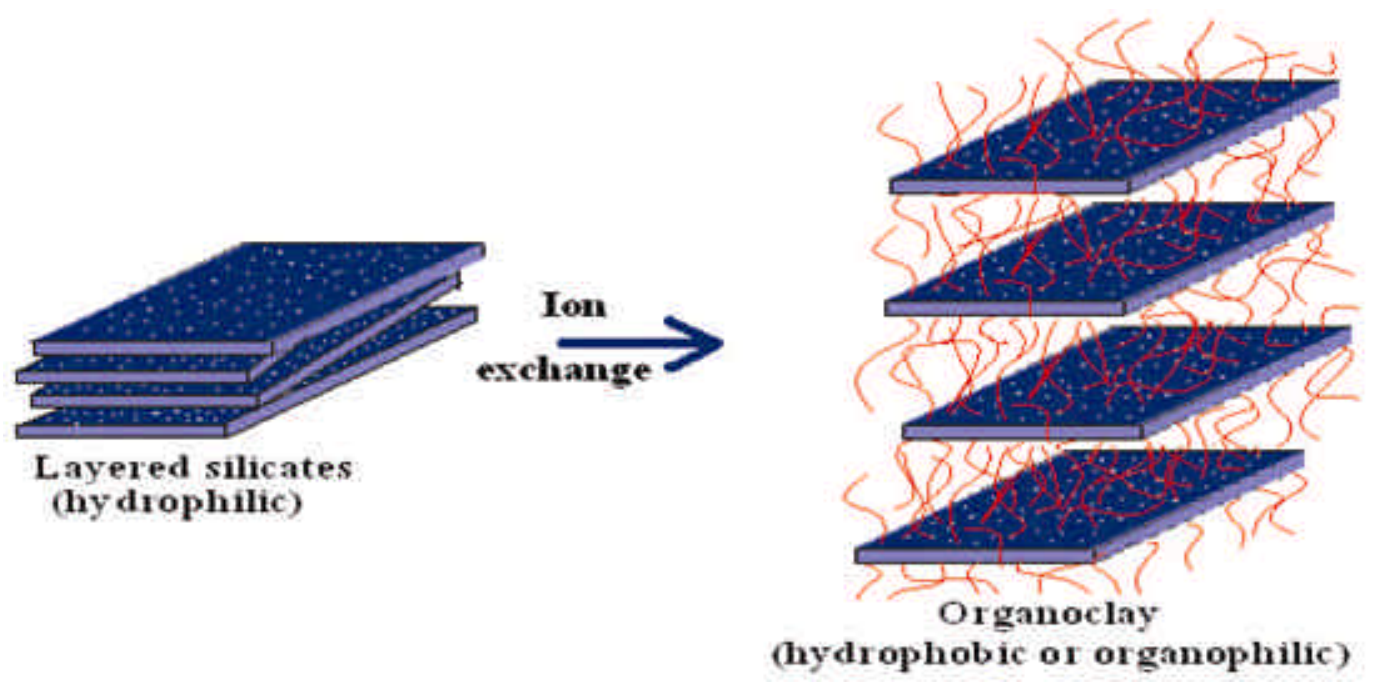

Figure 1. Schematic of an ion-exchange reaction in layered silicates.

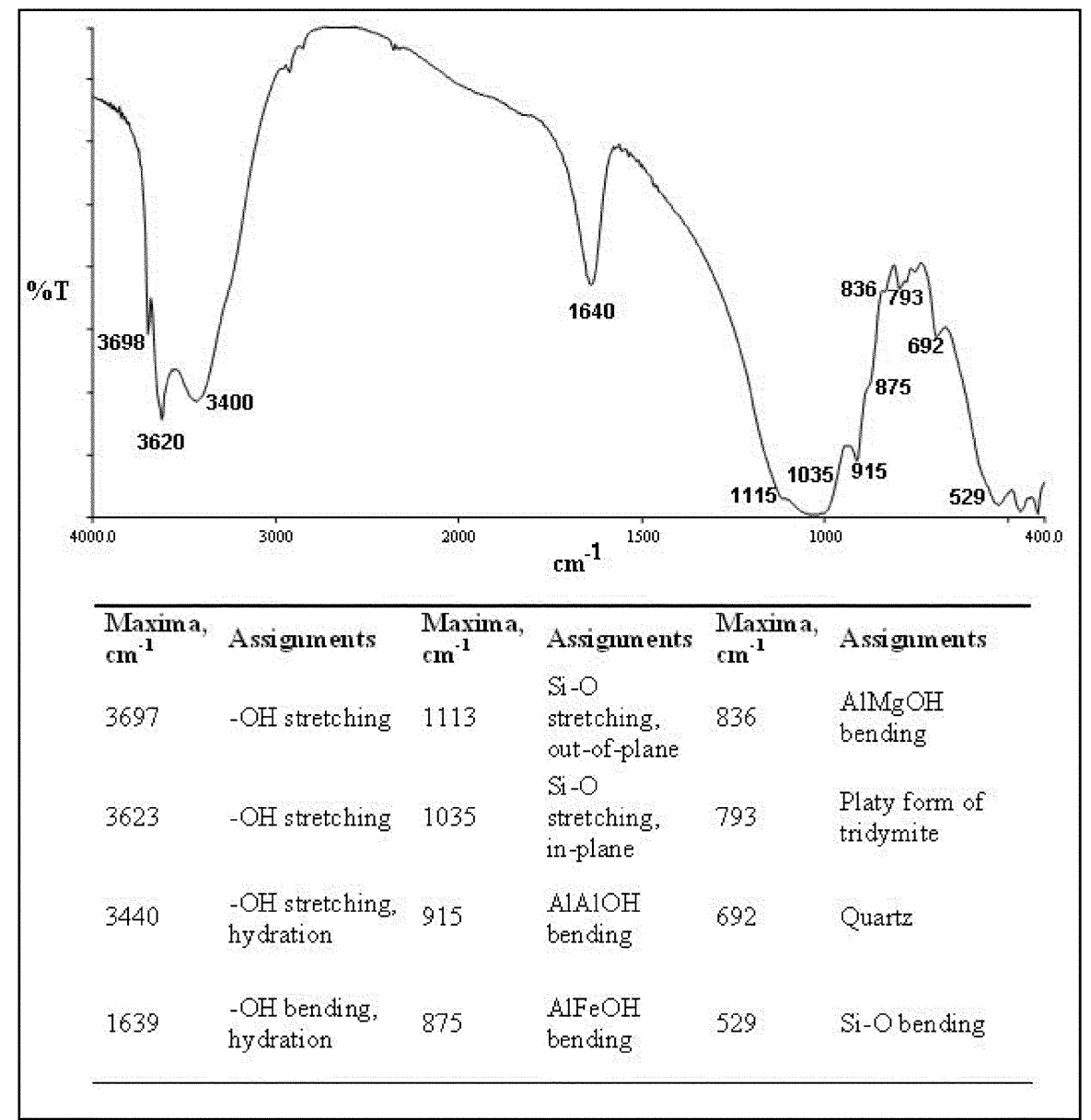

Figure 2. FT-IR spectrum of purified montmorillonite clay and its band assignments.

clay structure. The FTIR spectrum for montmorillonite clay recorded as $\mathrm{KBr}$ pellet and its band assignments are shown in figure 2.

The broad band centred near $3400 \mathrm{~cm}^{-1}$ is due to $-\mathrm{OH}$ stretching band for interlayer water. The bands at 3620 and $3698 \mathrm{~cm}^{-1}$ are due to $-\mathrm{OH}$ band stretch for $\mathrm{Al}-\mathrm{OH}$ and $\mathrm{Si}-\mathrm{OH}$. The shoulders and broadness of the structural $-\mathrm{OH}$ band are mainly due to contributions of several structural $-\mathrm{OH}$ groups occurring in the clay. However, the position of the maximum of the band is clearly indicative of the 
chemical composition of montmorillonite. The overlaid absorption peaks in the region of $1640 \mathrm{~cm}^{-1}$ in the FTIR spectrum of purified clay (montmorillonite) is attributed to $-\mathrm{OH}$ bending mode in water (adsorbed water). The characteristic peak at $1115 \mathrm{~cm}^{-1}$ is due to $\mathrm{Si}-\mathrm{O}$ stretching (out-of-plane) for montmorillonite. The peak at $1035 \mathrm{~cm}^{-1}$ is attributed to $\mathrm{Si}-\mathrm{O}$ stretching (in-plane) vibration for layered silicates. The IR peaks at 915,875 and $836 \mathrm{~cm}^{-1}$ are attributed to $\mathrm{AlAlOH}, \mathrm{AlFeOH}$ and $\mathrm{AlMgOH}$ bending vibrations, respectively (Madejova 2003; Patel et al 2005; Tyagi et al 2005; Xi et al 2005). An organically modified layered silicate indicates vibrational bands of organic modifier without causing any distortion of structure of clay.

PXRD is one of the most important techniques to determine the structural geometry, texture and also to illustrate impurities (kaolin, quartz, calcite, etc) in layered silicates which are present in clays.

Generally, the PXRD pattern (as shown in figure 3) indicates that there is presence of impurities such as kaolin $(\mathrm{K})$ and quartz $(\mathrm{Q})$ in raw montmorillonite which are partly or fully removed on further purification by sedi- mentation. The reflections relative to the planes [001] and [002] confirmed the presence of montmorillonite as main phase.

The X-ray diffractograms of the organoclay revealed a shift in the position of [001] planes ( $2 \theta$ changed from 5.7-4.32 degree), meaning an increase in the basal spacing of these planes. The increase was relatively large, from $1 \cdot 5-2 \cdot 05 \mathrm{~nm}$ and confirms the occurrence of organic molecule intercalation between silicate platelets. From the PXRD of figure 3, it is also observed that the peaks from [002] planes of montmorillonite, were not affected during treatment.

This observation highlights that the unique effect of organic modifier in layered silicates structure is the intercalation of [001] planes of montmorillonite. The basal spacing of layered silicates depends on the kind of organic modifier, with bulkier as well as high concentration of organic modifier and higher interlayer spacing results. The effect of types and concentration of organic modifier on properties of organoclay was studied by FT-IR, XRD and NMR spectroscopy and are well reported (Grim 1962; Lagaly 1981; Vaia et al 1994; Patel et al 2005).

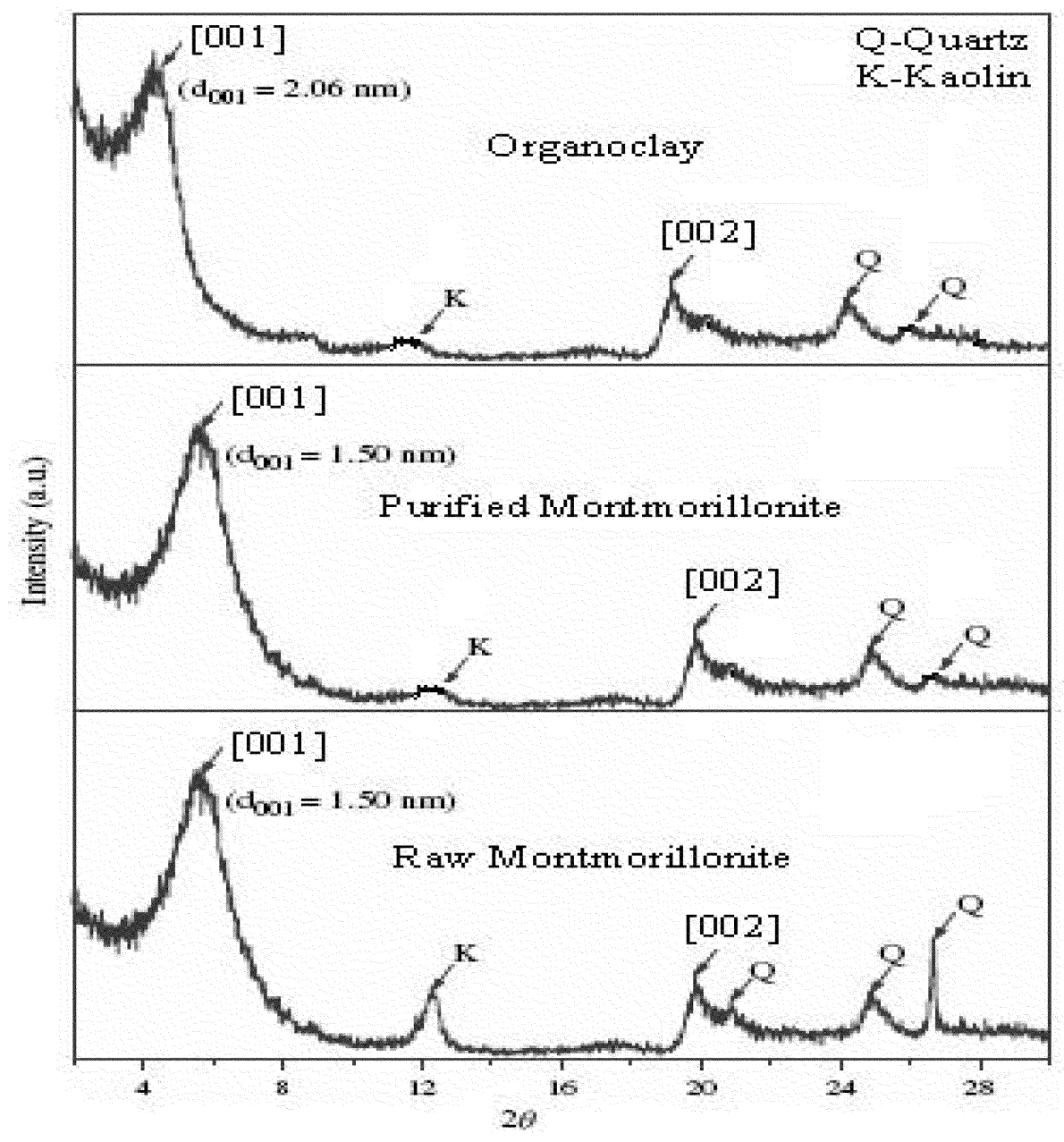

Figure 3. PXRD pattern for raw montmorillonite, purified montmorillonite and organoclay. 


\section{Polymer nanocomposites}

The role of alkyl ammonium cations in the organoclays is to lower the surface energy of the inorganic host and improve the wetting characteristics with the polymer. Additionally, the alkyl ammonium or phosphonium cations could provide functional groups that can react with the polymer or initiate polymerization of monomers to improve the strength of the interface between the inorganic and the polymer.

Polymer/layered silicate nanocomposites have attracted great interest, both in industry and in academia, because they often exhibit remarkable improvement in materials properties at very low clay content (3-6 wt\%), when compared with virgin polymer or conventional composites. The use of organoclays as precursors to nanocomposite formation has been extended into various polymer systems (thermoset and thermoplastic) including epoxy
(Chen et al 2003; Ratna et al 2003), polyimides (Delozier et al 2003; Nah et al 2003), rubber (Dai et al 1999; Su et al 2004), polyesters (Lee et al 2001; Wagener and Reisinger 2003), polyolefins (Manias et al 2001; Koo et al 2002; Lopez et al 2003; Ray and Okamoto 2003; Chang et al 2004), polystyrene (Hoffmann et al 2000; Manias et al 2000) and others. For true nanocomposites, the clay nanolayers must be uniformly dispersed and exfoliated in the polymer matrix. Once nanolayer exfoliation has been achieved, the improvement in properties can be manifested as an increase in tensile properties, as well as enhanced barrier properties, decreased solvent uptake, increased thermal stability and flame retardance (Okada et al 1990; Okada and Usuki 1995; Giannelis 1996; Wang et al 2003).

Three methods have been developed to produce polymer/layered silicate nanocomposites: in situ polymerization in which a polymer precursor or monomer are inserted in between clay layers and then expanding the layered

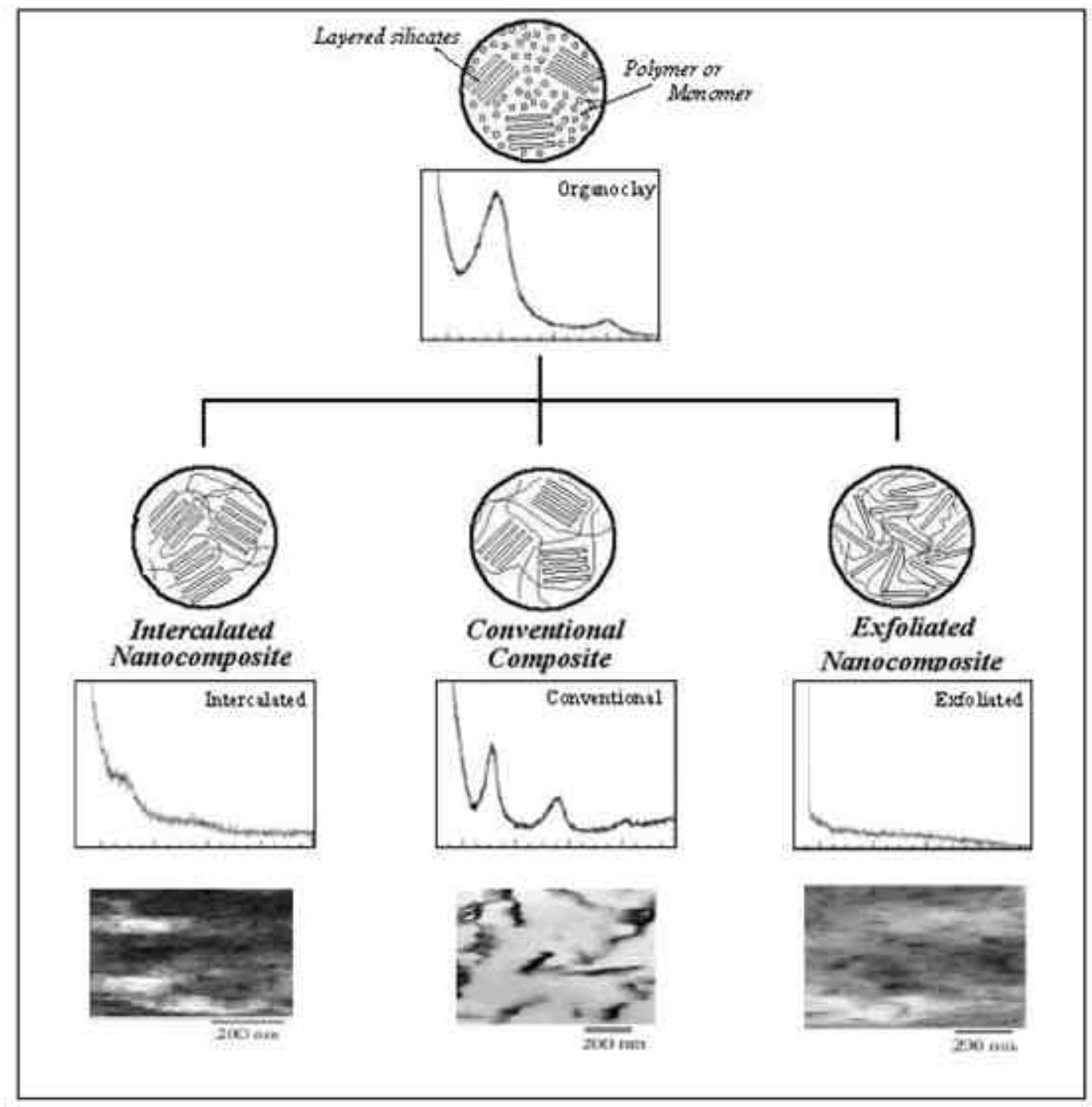

Figure 4. Three idealized structures of polymer/layered silicates composites with their WAXD patterns and TEM images. 
silicate platelets into the matrix by polymerization. This method has the advantage of producing well-exfoliated nanocomposites and have been applied to a wide range of polymeric systems; solution-induced intercalation method involves solvents to swell and disperse clays into a polymer solution and melt processing method applies intercalation and exfoliation of layered silicates in polymeric matrices during melt (Gao 2004). In addition to these three major processing methods, other fabrication techniques have also been developed. These include solid intercalation (Gao et al 2001), covulcanization (Usuki et al 2002), and the sol-gel method (Musto et al 2004).

Polymer layered silicate composites are ideally divided into three general types: conventional composites, intercalated nanocomposites and exfoliated nanocomposites as shown in figure 4 . The structure of polymer/layered silicates composites has typically been established using wide angle X-ray diffraction (WAXD) analysis and transmission electron micrographic (TEM) observation. WAXD is most commonly used to probe the nanocomposite structure because of its easiness and availability.

By monitoring the position, shape and intensity of the basal reflections from the distributed silicate layers, the nanocomposite structure (intercalated or exfoliated) may be identified. In an exfoliated nanocomposite, the extensive layer separation associated with the delamination of the original silicate layers in the polymer matrix results in the eventual disappearance of any coherent X-ray diffraction from the distributed silicate layers. On the other hand, for intercalated nanocomposites, the finite layer expansion associated with the polymer intercalation results in the appearance of a new basal reflection corresponding to the larger gallery height (Ray and Okamoto 2003).
Any physical mixture of a polymer and an inorganic material (such as clay) does not form a nanocomposite. Conventional polymer composites that are prepared by reinforcing a polymer matrix with inorganic materials like reinforcing fibres and minerals have poor interaction between the organic and the inorganic components, which leads to separation into discrete phases. Therefore, the inorganic fillers are required to be added in higher concentrations to achieve enhancements in the thermomechanical properties of the polymer (Galgali 2003). Table 1 shows a comparison of the physical properties of nanocomposites and conventional composites of polyamide. The reasons for the greater effectiveness of the nanoclay in polymer/layered silicates nanocomposites are two-fold: first, the nanoclay can be dispersed to the level of individual platelets. This nano scale dispersion of silicates provides very high surface area for polymer clay interaction. Secondly, the lamellar surfaces of the nanoclay can be modified through an ion exchange reaction to make them compatible with the polymer matrix.

The increasing demand of polymer/layered silicates nanocomposites which is one of the major markets for organoclays will help to open up many applications including automotive and packaging. It is estimated that (table 2) the demand for polymer nanocomposites materials will be worth over 1 billion pounds by 2009 .

\section{Rheological modifier}

Rheological modifiers control the flow properties of liquid systems such as paints, inks, emulsions or pigment suspensions by increasing the medium viscosity or impart thixotropic flow behavior to liquid system. Several dis-

Table 1. Comparison of mechanical and physical properties of nylon-6 nanocomposites and conventional composites.

\begin{tabular}{lcccc}
\hline Materials properties & $\begin{array}{c}\text { Pristine } \\
\text { nylon-6 }\end{array}$ & $\begin{array}{c}3-6 \% \\
\text { Organoclay }\end{array}$ & $\begin{array}{c}30 \% \\
\text { Mineral }\end{array}$ & $\begin{array}{c}30 \% \\
\text { Glass fibre }\end{array}$ \\
\hline Tensile strength (psi) & 7250 & 11800 & 8000 & 23000 \\
Flexural modulus (psi) & 120 & 500 & 650 & 1000 \\
Notched izod impact strength $(\mathrm{J})$ & $1 \cdot 2$ & $1 \cdot 2$ & 1.6 & 1.8 \\
Heat deflection temperature $\left({ }^{\circ} \mathrm{C}\right)$ & 66 & 110 & 120 & 194 \\
Specific gravity (g/cc) & $1 \cdot 3$ & $1 \cdot 14$ & 1.36 & 1.35 \\
\hline
\end{tabular}

Table 2. Estimated market size by 2009.

\begin{tabular}{|c|c|}
\hline Technology/application & Estimated market size* (by 2009) \\
\hline Polymer/clay nanocomposites & Over 1 billion pounds \\
\hline Packaging & 367 million pounds \\
\hline Automotive & 345 million pounds \\
\hline Building and construction & 151 million pounds \\
\hline Coatings & 63 million pounds \\
\hline Industrial & 48 million pounds \\
\hline Others & 67 million pounds \\
\hline
\end{tabular}

*Source: Argonne National Laboratory, USA 
persion procedures are used for conventional organoclays; however, they all can be described by two general procedures, viz. pre-gel addition and dry addition. Using either of these procedures, dispersion is usually carried out under shear. The pre-gel method involves making 10$15 \%$ organoclays (depending on its gel volume) dispersion in a suitable solvent using a high-speed disperser and a polar activator. Pre-gels can be made in large batches, stored and used as needed, or as the first step in the manufacturing process. Direct addition of organoclays involves adding organoclay as a dry powder prior to, or during, the grind phase in the manufacturing process. The most advantageous is the addition of resin and solvent. This will allow the organoclay to wet out. Polar activator is then added and dispersion continued. In the wet out step, organoclay is introduced to solvent under shear. This will cause a partial deagglomeration of the platelets, but by no means complete dispersion. For complete dispersion to occur, the addition of a polar activator is necessary. The function of polar activators is to disrupt the weak Van der Waal forces which tend to hold the clay platelets together. Once these platelets are separated, it allows the organic functional groups to free themselves from close association with the clay surface. These functional groups are now free to solvate in the organic liquid; i.e. they have a much higher affinity for the organic solvent than the inorganic clay surface (schematic 2). These functional groups are part of the organic modifier that is attracted to the clay surface through electrostatic forces (Edwin 1990; Gadberry et al 1997).

The typical structure of organoclay consists of layered silicate platelet having a long-chain organic compound bonded to its two faces. In a system containing the fully dispersed and activated organoclay additives, a gel structure is developed by edge-to-edge hydrogen bonding between hydroxyl groups on the organoclay platelet edges. Solvation of the long-chain organic molecule tails makes them stand away from the clay platelet faces. In most cases a chemical activator (also known as polar activator) is added to ensure complete delamination, dispersion, and full activation of the organoclay; however, polar activator free organically modified layered silicates had also been developed by subsequently ion exchanged organic modifier with polar functional groups. Polar activators are defined as low molecular weight compounds of a polar nature. The most commonly used polar activators are propylene carbonate, methanol/water and ethanol/water mixture. Acetone is an excellent polar activator but it is seldom used today due to safety and environmental concerns. Several other low molecular alcohols are also used as polar activator in the industry. While all the polar activators are highly efficient, the methanol/water or ethanol/water combinations are most frequently used due to cost considerations in paint formulation, however, propylene carbonate/water mixture is best suitable for formulating high temperature resistant greases. An optimum amount of polar (chemical) activator must be used to avoid problem of reduction in gel strength. If not enough polar activator is used, then even with the application of shear not all the platelets will be wedged apart. This will result in partial delamination and inadequate gel strength as shown in figures 5a, b. An excessive level of polar activator interferes with hydrogen bonding and weakens the gelation forces leading to a reduction in gel strength (Somani et al 1999, 2000).

It should also be noted that when using an alcohol as a polar activator, it must contain atleast $5 \%$ water. If water is absent, the polar activator will not function efficiently, thus reducing final product performance. A little is gained by omitting the $5 \%$ water addition. Poor gel strength development without the water addition indicates that not enough water molecules were available to form a bridge between the hydroxyls on organoclay platelet edges. There are three main types of mechanisms that occur while adding organoclay into solvent based system: hydrogen bridging or $\mathrm{OH}$-bonds formation, associativity space orientation which results into gel structure as shown in schematic 2. The rheological properties of the paint system are enhanced by small addition of organoclays either by pre-gel or dry addition as discussed above. The gel formation prevents pigment settling and sagging on vertical surfaces to ensure that the proper thickness of the

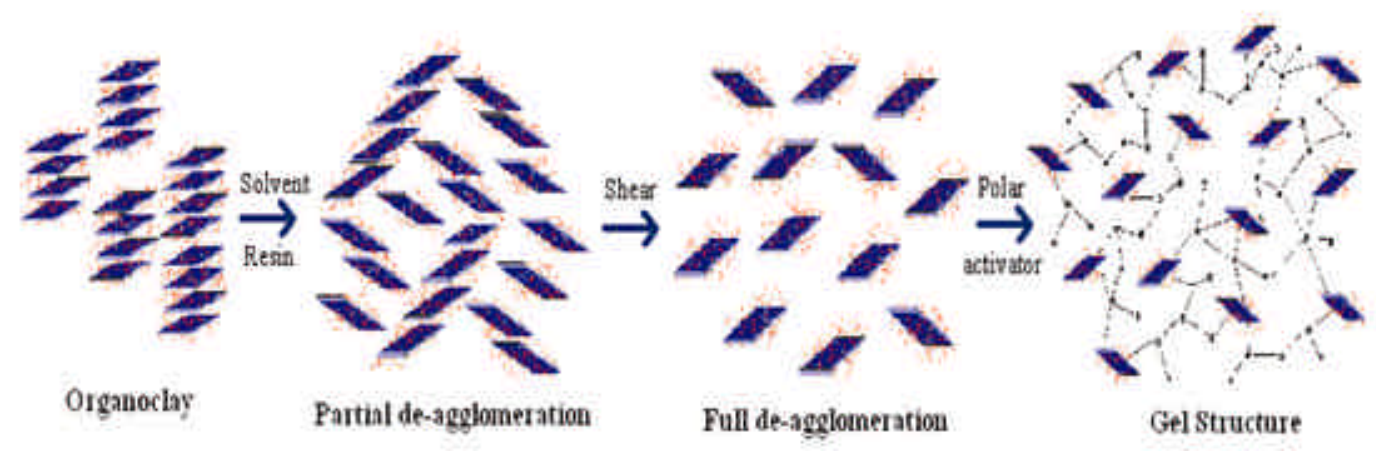

Schematic 2. Mechanism of gel formation. 

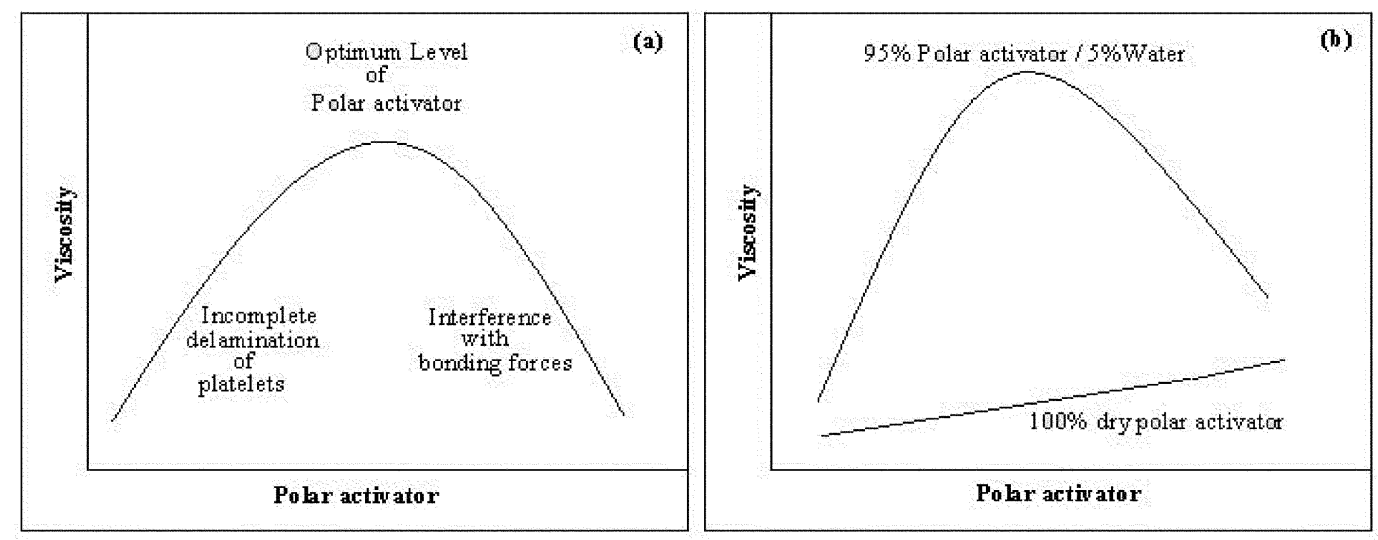

Figure 5. (a) Effect of amount of polar activator on viscosity and (b) effect of polar activator/water on viscosity of fluid system.

\section{Ease of Application}

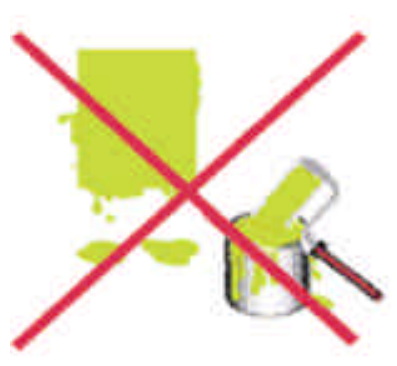

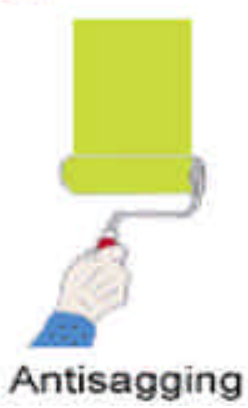

Formulation Stabilization

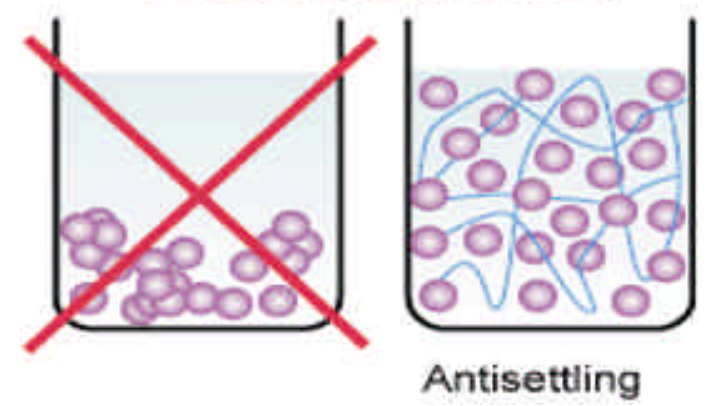

Schematic 3. Incorporation of small amount of organoclay improves antisagging and antisettling properties in paints and inks.

coating is applied as shown in schematic 3. They also ensure good leveling for the removal of brush marks and storage stability even with high temperatures. Organoclay is used in the ink formulation. It helps to adjust the consistency of printing inks to the desired values, avoiding pigment sedimentation, providing good colour distribution, obtaining desired film thickness, reduction in misting, control of tack, water pickup and dot gain control by incorporation of small amount of organically modified layered silicates.

Thickening lubricating oils with organoclays can produce specially high temperature resistant lubricating greases. Organoclay also gives good working stability and water resistance to the greases. Such greases are typically used for lubrication in foundries, mills and on high-speed conveyors, agriculture, automotive and mining (Somani et al 1999, 2000). The performance of cosmetics is enhanced by the use of organoclays and they allow good colour retention and coverage for nail lacquers, lipsticks and eye shadows. They have been tested to be nonirritant for both skin and eye contact (Tatum and Wright 1988; Gadberry et al 1997). The applicability of organoclays as rheological modifiers in paints, inks, grease and cosmetics are shown in schematic 4 .

\section{Nanoclay as drug vehicle}

The continuous development of new controlled drug delivery systems is driven by the need to maximize therapeutic activity while minimizing negative side effects. One class of drug delivery vehicle that has received more attention in recent years is layered materials which can accommodate polar organic compounds between their layers and form a variety of intercalated compounds. Because the release of drugs in drug-intercalated layered materials is potentially controllable, these new materials have a great potential as a delivery host in the pharmaceutical field. Calcium montmorillonite has also been used extensively in the treatment of pain, open wounds, colitis, diarrhea, hemorrhoids, stomach ulcers, intestinal problems, acne, anemia, and a variety of other health issues. Not only does montmorillonite cure minor problems such as diarrhea and constipation through local application, it also acts on all organs as well (Forni et al 1989; Sekine et al 1999; Fejé et al 2001; Lin et al 2002; Lee and Fu 2003; Lee and Chen 2004).

Yuancai and Si-Shen (2005) described the novel poly (D,L-lactide-co-glycolide)/montmorillonite nanoparticle drug 
delivery system, formulating the drug carrier from a material, which can also have therapeutic effects, either synergistic with or capable to mediate the side effects of the encapsulated drug. Paclitaxel (anticancer drug)-loaded poly (D,L-lactide-co-glycolide)/montmorillonite nanoparticles were prepared by the emulsion/solvent evaporation method and was tested for in vitro drug release. The initial burst of $22 \%$ on the first day can be observed for sample. After that, the release of paclitaxel was at a slow constant rate. In three weeks, about $36 \%$ drug was released with a slightly reduced initial burst and speed release as shown in figure 6a (Yuancai and Si-Shen 2005). The adsorption and desorption of organic molecules and surfactants on layered silicates indicates that these materials can be used for drug delivery. The release of buformin from buformin/montmorillonite complex and pure buformin hydrochloride in artificial intestinal juice over $360 \mathrm{~min}$ is presented in figure $6 \mathrm{~b}$.

Buformin/montmorillonite complex released $70 \%$ of buformin with lower rate as compared to pure compound in $360 \mathrm{~min}$ (Fejé et al 2001). Medical devices such as a drug delivery patch, implantable or insertable medical device comprise of polymer carrier (as matrix) and drug intercalated layered silicates (as reinforcement) provides controlled release of therapeutic agent to damaged cell of a patient (Sheng-Ping 2005).

In addition to surface unmodified and modified montmorillonite, layered double hydroxides are also used as drug carrier in various applications. Intercalation of fenbufen in a layered double hydroxide followed by coating with Eudragit@ S 100 gives a composite material which shows controlled release of the drug under in vitro conditions which model the passage of a material through the gastrointestinal tract (Sheng-Ping 2005). Intercalations of anti-inflammatory drug in layered double hydroxide have the advantage of gradual release over a longer period of time (Bingxin et al 2004a, b; Min et al 2004). Gene the- rapy is gaining growing attention for the treatment of genetic deficiencies and life-threatening diseases. For the efficient introduction of foreign DNA into cells, a carrier system is required. Recently, it has been successfully demonstrated that novel layered double hydroxide could form a nanohybrid by intercalating with bimolecular anion such as mononucleotides, DNA which shows that antisense oligonucleotide molecules packaged in the layered double hydroxide can enter cells, presumably through phagocytosis or endocytosis. The leukemia cells were used to explore the layered double hydroxide's potential as gene carriers (Seo-Young et al 2002).

\section{Wastewater treatment}

The use of organoclays in wastewater treatment has become common in industry today. Organoclays exhibit a synergistic effect with many commonly utilized water treatment unit processes including granular-activated charcoal, reverse osmosis, and air strippers. Granular-activated carbon is particularly effective at removing a large range of organic molecules from water, however, is very poor for removing large molecules such as humic acid and wastewaters containing emulsified oil and grease. Organoclays have proven to be the technology of choice for treating oily wastewaters (Speed et al 1987; Jasra et al 1999). Humic acid is one of the common contaminant in potable water and is difficult to remove with conventional flocculation techniques commonly used for drinking water treatment and activated carbon is very ineffective due to its weak interaction with humic acid. The comparative studies for removal efficiencies of humic acid from ground water using different sorbents are shown in figure 7.

If humic acid is not removed from drinking water, subsequent chlorination produces unacceptable levels of trihalomethanes which are known carcinogens.
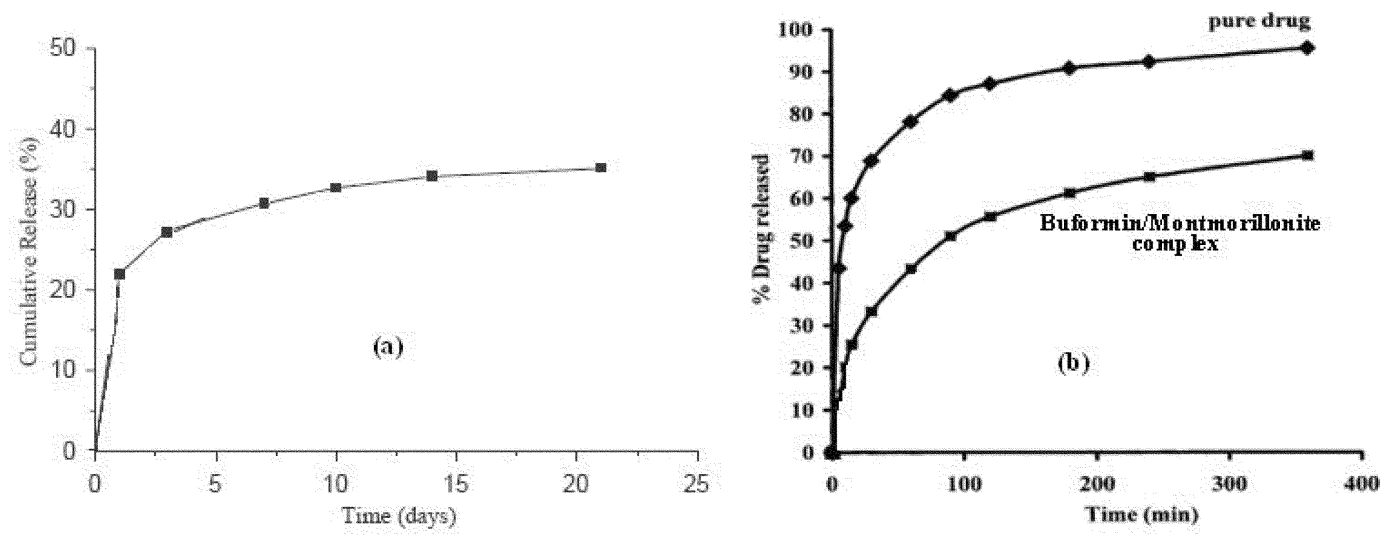

Figure 6. (a) In vitro drug release of the paclitaxel-loaded poly (D,L-lactide-co-glycolide)/montmorillonite nanoparticles and (b) rate of desorption of buformin from the buformin hydrochloride and buformin/montmorillonite complexes in artificial intestinal juice. 

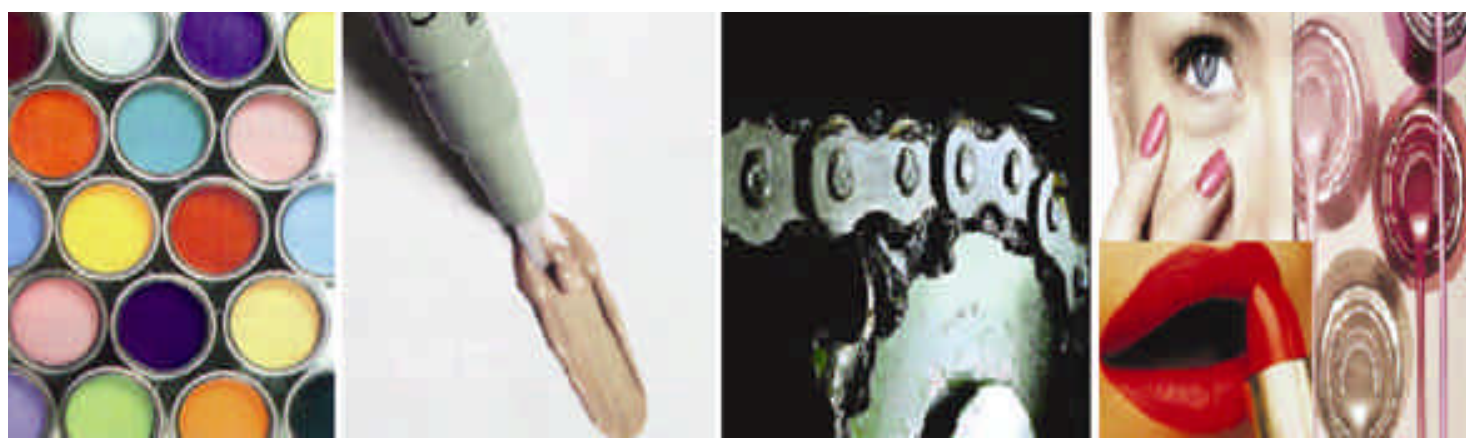

Schematic 4. Fields of application (paints, inks, greases and cosmetics).

Table 3. Comparison of alum flocculation and organoclay treatment.

\begin{tabular}{lcccc}
\hline Type sample & $\mathrm{pH}$ & $\begin{array}{c}\text { Turbidity } \\
\text { (NTU) }\end{array}$ & $\begin{array}{c}\text { Oil and grease } \\
(\mathrm{ppm})\end{array}$ & Appearance \\
\hline Untreated water (a) & $6 \cdot 6$ & $18 \cdot 0$ & 52 & Turbid \\
$\quad$ (a) Treated with alum-NaOH-polymer & $8 \cdot 0$ & $0 \cdot 4$ & 32 & Clear \\
Untreated water (b) & $7 \cdot 1$ & $15 \cdot 0$ & 62 & Turbid \\
$\quad$ (b) Treated with organoclay & $7 \cdot 1$ & $<0 \cdot 4$ & $<2$ & Clear \\
\hline
\end{tabular}

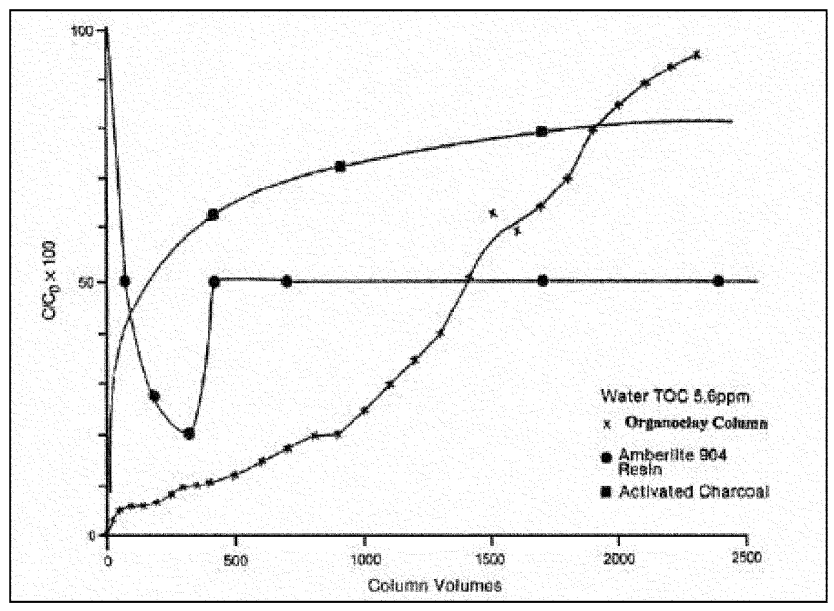

Figure 7. Sorbents (organoclay, amberlite 904 resin and activated charcoal) removal efficiencies for humic acid from ground water.

The ability of organoclays to sorbs organics was studied by McBride et al (1975) and Kokai (1975). They concluded that 1 litre of water containing 12,000 ppm of oil reduced to $12 \mathrm{ppm}$ by addition of $10 \mathrm{~g}$ of organoclays.

Partitioning is the mechanism responsible for the sorption of organics by organoclays. The organoclay contains alternating organic and inorganic layers. The organic layer is comprised of the quaternary ammonium compounds ion exchanged on the surface. This hydrophobic layer acts as an organic phase into which organic substances that are dissolved in water can partition. The partitioning efficiency should be a function of water solubility of the organic substance since the two phases available to it are water and the quaternary compound in the gallery of the clay.

Organoclay is one of the ideal materials for treating industrial waste water. In the process of manufacturing heater coils, as part of their quality control (QC), the company leak tests each unit. The leak testing is conducted by pressurizing the coils while they are submersed in large tanks of water. Since the leaks are spotted visually, the water in the tanks must be as clear as possible. As more and more coils are tested, residual Parco88 oil utilized in the manufacturing process builds up in the water, causing the turbidity to climb rapidly. In the past, the test tanks required frequent dumping and refilling, causing problems with discharge of the oily water and the expense of additional water to refill the test tanks. In the initial testing of treatment alternatives for this water, three processes were studied which included $\mathrm{pH}$ adjustment, alum flocculation and organoclay column treatment. It was found that $\mathrm{pH}$ adjustment was totally ineffective. The alum flocculation test worked reasonably well; however, this process required substantial outlays for equipment and allocation of space, plus a solid waste stream would be produced requiring disposal (Beall 2003).

The disposal of such sludges is becoming increasingly more difficult and expensive. The disposal of such waste also leaves the waste generator with a potential long-term liability. The best alternative tested was column treatment of the waste with organoclay. A comparison of the results obtained from the alum/ $\mathrm{NaOH} /$ polymer flocculation and organoclay column test is shown in table 3. As can be seen in the results, the organoclay treatment yielded superior clarity and oil and grease removal when compared to the alum treatment. In addition to leak test tank waste 
water treatment, organoclays can be extensively used to treat military base effluent, oil well acid returns, boiler feed water, steam condensate among others.

\section{Conclusions}

Significant progress in the development of clay/polymer nanocomposites has been made over the past fifteen years. The advantages and limitations of the technology have become clear. However, we have a long way to go before we understand the mechanisms of the enhancement of major engineering properties of polymers and can tailor the nanostructure of these composites to achieve particular engineering properties. Finally, the fact that clay/polymer nanocomposites show concurrent improvement in various material properties at very low filler content, together with the ease of preparation through simple processes such as melt intercalation, melt extrusion or injection molding, opens up a new dimension for plastics and composites. Organoclays as rheological modifier is one of the oldest methodologies in industries and have been extensively used worldwide. The development of polar activator free organoclays in last 10 years made tremendous impact in the field of paint, ink and greases. Although the field of nanoclays as drug vehicle for controlled release of drug is one of the born age area in medicinal application, nanoclays have great potential as compared to polymer and carbon nanotubes for drug delivery applications. The use of organoclays has proven to be very viable for many water treatment applications. Organoclays operate via partitioning phenomena and have a synergistic effect with activated carbon and other unit processes such as reverse osmosis. They have proven to be superior to any other water treatment technology in applications where the water to be treated contains substantial amounts of oil and grease or humic acid. The commercial application of organoclays to trihalomethane control in drinking water has not yet occurred. With increasing concerns about the carcinogenic effects of trihalomethanes, the commercialization of this technology could be around the corner.

\section{Acknowledgements}

We thank Dr P K Ghosh, Director, Central Salt \& Marine Chemicals Research Institute, Bhavnagar, for taking keen interest in this work and also providing the facilities; to CSIR for funding under Network project, COR 004.

\section{References}

Beall G W 2003 Appl. Clay Sci. 2411

Bhatt J G, Mody H M and Bajaj H C 1996 Clay Res. 1528

Bhatt J G, Jasra R V and Ghosh P K 2005 Indian Patent application (submitted)

Bingxin L, Jing H, David G E and Xue D 2004a Int. J. Pharmaceutics 28789
Bingxin L, Jing H, David G E and Xue D 2004b Appl. Clay Sci. 27 199

Biswas M and Sinha Ray S 2001 Adv. Polym. Sci. 155167

Boricha A B, Mody H M, Das A and Bajaj H C 1999 Appl. Cat. A5 179

Chen C, Khobai M and Curliss D 2003 Prog. Org. Coat. 47376

Chang J, Kim S, Joo Y and Im S 2004 Polymer 45919

Dai J C and Huang J T 1999 J. Appl. Clay Sci. 1551

Delozier D M, Orwoll R A, Cahoon J F, Ladislaw J S, Smith Jr J G and Connell J W 2003 Polymer 442231

Edwin S 1990 US Patent 509859

El-Nahhal Y Z and Safi J M 2004 J. Colloid Int. Sci. 269265

Fejér I, Kata M, Erös I, Berkesi O and Dékány I 2001 Colloid. Polym. Sci. 2791177

Forni F, Lannuccelli V, Coppi G and Bernabei M T 1989 Arch. Pharm. 322789

Fukushima Y and Inagaki S 1987 J. Inclusion Phenom. 5473

Gadberry J F, Hoey M and Powell C F 1997 US Patent 566311

Galgali G 2003 Synthesis-structure-processing-property relationship in polymer nanocomposites, $\mathrm{Ph} \mathrm{D}$ thesis, National Chemical Laboratory, Pune

Gao F 2004 Mater. Today 1150

Gao F, Chen S and Hull J B 2001 J. Mater. Sci. Lett. 201807

Giannelis E P 1996 Adv. Mater. 829

Giannelis E P, Krishnamoorti R K and Manias E 1999 Adv. Polym. Sci. 138107

Grim R E 1953 Clay mineralogy (New York: McGraw Hill Book Company)

Grim R E 1962 Applied clay mineralogy (New York: McGrawHill Book Co. Inc.)

Halligudi S B, Bajaj H C, Bhatt K N and Krishnaratnam M 1992 React. Kinet. Cat. Lett. 48547

Hoffmann B, Dietricha C, Thomann R, Friedrich C and Mulhaupt R 2000 Macromol. Rapid Commun. 2157

Irene M C and Raymond K M 1998 Water Sci. \& Technol. 38143

Jasra R V, Kumar P and Bhat S G T 1995 Ind. Engg. Chem. Res. 42351

Jasra R V, Bajaj H C and Mody H M 1999 Bull. Cat. Soc. India 9113

Kokai T 1975 Japanese Patent Application 25489

Koo C, Ham H, Kim S, Wangand K, Chung I, Kim D and Zin W 2002 Macromolecules 355116

Lagaly G 1981 Clay Min. 161

Lagaly G 1986 Solid State Ionics 2243

LeBaron P C, Wang Z and Pinnavaia T J 1999 Appl. Clay Sci. 1511

Lee S, Park H, Lim H, Kang T, Li X, Cho W and Ha C 2001 Polymer 432495

Lee W F and Fu Y T 2003 J. Appl. Polym. Sci. 893652

Lee W F and Chen Y C 2004 J. Appl. Polym. Sci. 912934

Lin F H, Lee Y H, Jian C H, Wong J M, Shieh M J and Wang C Y 2002 Biomaterials 231981

Lopez D, Picazo O, Merino J and Pastor J 2003 Eur. Polym. J. 39945

Madejova J 2003 Vibrat. Spectrosc. 311

Manias E, Touny A, Wu L, Lu B, Strawhecker K, Gilman J and Chung T 2000 Polym. Mater. Sci. \& Eng. 82282

Manias E, Touny A, Wu L, Strawhecker K, Lu B and Chung T 2001 Chem. Mater. 133516

McBride M B, Pinnavaia T J and Mortland M M 1975 Adsorption of aromatic molecules by clays in aqueous suspensions, 
Presented at the National Meeting of the American Chemical Society (Columbus: ACS Publication) 15 p. 44

Min W, Shuxian S, Ji W, Yong L and Xue D J 2004 Solid State Chem. 1772534

Musto P, Ragosta G, Scarinzi G and Mascia L 2004 Polymer 451697

Nah C, Han S, Lee J, Lee M, Lim S and Rhee J 2003 Composites: Part B 35125

Okada A and Usuki A 1995 Mater. Sci. Eng. C 3109

Okada A, Kawasumi M, Usuki A, Kojima Y, Kurauchi T and Kamigaito O 1990 MRS Symposium Proceedings (Pittsburgh: Materials Research Society) 171 p. 45

Patel H A, Somani R S, Bajaj H C and Jasra R V 2005 J. Mater. Sci. (communicated).

Ratna D, Becker O, Krishnamurthy R, Simon G P and Varley R J 2003 Polymer 447449

Ray S and Okamoto M 2003 Prog. Polym. Sci. 281539

Sanchez-Martin M J, Rodriguez-Cruz M S, Andrades M S and Sanchez-Camazano M 2005 Appl. Clay Sci. 31216

Sekine T, Yoshida K, Matsuzaki F, Yanaki T and Yamaguchi M 1999 J. Surf. Deter. 2309

Sheng-Ping Z 2005 US Patent 0181015 A1

Seo-Young K, Yong-Joo J, Jong-Sang P and Jin-Ho C 2002 Solid State Ionics 151229

Slabaugh W H and Hanson D B 1969 J. Colloid \& Int. Sci. 29460

Somani R S, Shukla D B, Bhalala B J, Mehta A S and Jasra R V 1998 Technical Report, Indian Oil Corporation, R\&D Centre, Faridabad

Somani R S, Shukla D B and Bhalala B J 2000 Indian Patent NF No. 572/DEL/2000
Sora I N, Pelosato R, Zampori L, Botta D, Dotelli G and Vitelli M 2005 Appl. Clay Sci. 2843

Speed M A, Barnard A, Arber R P, Budd G C and Johns F J 1987 EPA 600 S2-87 011

Stockmeyer M R 1991 Appl. Clay Sci. 639

Su S, Jiang D and Wilkie C 2004 Polym. Degrad. \& Stab. 84279

Taqui Khan M M, Samad S A, Siddiqui M R H, Bajaj H C and Ramachandraiah G 1991 Polyhedron 102729

Tatum J P and Wright R C 1988 US Patent 4752342

Theng B K G 1979 Formation and properties of clay-polymer complexes (Amsterdam: Elsevier Publication)

Theng B K G 1974 The chemistry of clay-organic reactions (New York: John Wiley \& Sons Inc.)

Tyagi B, Chudasama C D and Jasra R V 2005 Spectrochimica Acta Part A (in press)

Usuki A, Tukigase A and Kato M 2002 Polymer 432185

Vaia R A, Ishii H and Giannelis E P 1993 Chem. Mater. 5 1694

Vaia R A, Teukolsky R K and Giannelis E P 1994 Chem. Mater. 6 1017

Vaia R A, Price G, Ruth P N, Nguyen H T and Lichtenhan 1999 J. Appl. Clay Sci. 1567

Wagener R and Reisinger T 2003 Polymer 447513

Wang D and Wilkie C 2003 Polym. Degrad. \& Stab. 82309

Worrall W E 1986 Clays and ceramic raw materials (London: Elsevier Applied Science Publishers) IInd edn.

Xi Y, Ding Z, Hongping H and Frosr R L 2005 Spectrochimica Acta Part A $\mathbf{6 1 5 1 5}$

Yuancai D and Si-Shen F 2005 Biomaterials 266068 